\title{
The Theoretical Logic and Practical Basis of the Supply-Side Reform of Sports Industry
}

\author{
Bingchuan Sun \\ Physical Education College \\ Shandong University of Finance and Economics \\ Ji'nan, China
}

\author{
Yuanxiang Liu \\ Shandong Sport University \\ Ji'nan, China
}

\begin{abstract}
Since the mismatch between supply and demand has become a constraint to the development of sports industry, it has become an academic consensus to accelerate the supplyside structural reform of sports industry. In this paper, literature, expert interviews, mathematical statistics, logical analysis and other research methods are adopted from the relationship between the supply side and the demand side of the sports industry to clarify the logical starting point of the supply-side reform of sports industry. This paper analyzes the realistic basis of the supply-side structural reform of the sports industry from the aspects of the quantity, quality and efficiency of the supply of sports products. It puts forward the reform paths to strengthening the interaction feedback of supply and demand, deepening the reform of management system, improving the supply system of sports products, increasing total factor productivity, promoting the integrated development of "sports + " and extending the sports industry chain.
\end{abstract}

Keywords—sports industry; the supply side; theoretical logic; realistic basis

\section{INTRODUCTION}

With the transformation and upgrading of residents' consumption structure, the mismatch between supply and demand of sports products becomes increasingly significant, resulting in the sluggish growth of sports industry. In 2015, the central government made a comprehensive assessment of the economic situation and made major theoretical innovations and decisions of supply-side structural reform, which were adapted to all areas of economic development. The necessity and trend of supply-side structural reform of sports industry have also become the consensus of academia, politics and business circles. Yet the logic and depth of the reform is unclear. This paper attempts to explore the theoretical logic and mechanism of the supply-side reform of the sports industry, the theoretical connotation and practical path, and provide effective ideas and feasible countermeasures for promoting the supply-side structural reform of the sports industry.

\section{LOGICAL StARTING POINT: ClARIFYING (GRASPING) THE RELATIONSHIP BETWEEN THE SUPPLY SIDE AND THE DEMAND SIDE OF SPORTS INDUSTRY}

China's economic growth faces both matters of supply and demand. On the supply side of the development of sports industry in the middle economic level, there are problems such as mismatches of production factors, low total factor productivity and low supply quality; and the demand side is faced with the coexistence of residents' consumption upgrade and insufficient effective demand for sports consumption. As a result, sports industry contributes little to China's economic development, for which there are reasons from the two aspects of supply and demand.

\section{A. Interdependent Economic Theories}

In the Introduction to the "Critique of Political Economy", Marx dialectically discusses the interrelationship between supply (production) and demand (consumption) in the process of social reproduction. Marx points out: "Each side of production and consumption is the means of the other, with the other as the medium, which is reflected in their interdependence." In the process of evolving economic growth, the four elements on the supply side (labor, land, capital and technological innovation) and the three driving forces on the demand side (consumption, investment and exports) interact, co-evolve and determine the direction and speed of economic growth. The "troika" of the demand side starts from the operation result, which is convenient for short-term counter-cyclical adjustment of macro-control. The supply side starts from the source of operation and tries to provide sustainable impetus for economic development by optimizing the allocation of production factors.

\section{B. Consistent Policy Logic}

Supply-side reform and demand-side management are not an either/or choice. Economic effect is the result of both sides' efforts. The logic of central policy is consistent, emphasizing supply and demand management from beginning to end. In 2015, general secretary Xi Jinping proposed at the central work conference that "while appropriately expanding aggregate demand, efforts should be made to strengthen supply-side structural reform and improve the quality and efficiency of the supply system, so 
as to enhance the driving force for sustained economic growth". At a meeting on the Formulation of the "13th FiveYear Plan", Premier Li Keqiang said, "Efforts should be made on both the supply side and the demand side to promote the industry to the medium-high end." After the State Council issued "Some Suggestions on Accelerating the Development of Sports Industry and Promoting Sports Consumption" in 2014, it gradually expanded and refined sports industry development policies have been issued and implemented, which can be divided into supply-side and demand-side policies according to the implementation objects.

1) The supply-side policy aims to optimize the allocation of production factors so as to enrich and improve the quantity and quality of sports products: The supply-side policy of sports industry aims to optimize the allocation of production factors such as venues, capital and technology to enrich and improve the quantity and quality of sports product supply. The examples are Guiding Suggestions on Accelerating the Development of Sports Competition Performance Industry" launched by General Office of the State Council, "Notice on Promoting Free and Low-cost Opening of Large Stadiums and Gymnasiums" issued by the General Administration of Sport of China, "Measures for the Administration of Guiding Funds for the Development of Sports Industry" issued by provinces and cities, the state general administration of sports on the large sports venues open free low charge notice, various provinces and cities "sports industry development guidance funds management method", the "Opinions on Policies and Measures to Promote Mass Entrepreneurship and Innovation" of the State Council, and the "Development Plan for Outdoor Sports Projects Such as Marathon, Ice and Snow, and Bicycle", etc. That means using reform to promote structural adjustment, correct distortions in the allocation of factors, expand effective supply, make the supply structure more adaptable and flexible to changes in demand and raise total factor productivity, so as to better meet the needs of the people and promote sustained and sound economic and social development.

2) The demand-side policy aims to promote residents' sports consumption, so as to expand domestic demand and promote economic restructuring and upgrading: The demand-side policy is aimed at promoting residents' sports consumption, giving further play to the sports industry in expanding domestic demand and promoting economic restructuring and upgrading. Examples are "Action Plan to Further Promote Sports Consumption (2019-2020)" jointly issued by the General Administration of Sport of China and the National Development and Reform Commission, "Opinions on Further Expanding Consumption in Tourism, Culture, Sports, Health, Old-age Education and Training", "Implementation Plan for Improving the System and Mechanism for Promoting Consumption (2018-2020)" and the "Suggestions on Further Expanding Consumption in Such Areas as Tourism, Culture, Sports, Health, Old-age
Education and Training" of the General Office of the State Council, etc. Listing the sports industry as a key industry related to people's happiness, they are drew up to break down the institutional barriers to consumer spending, promote the integrated development of sports and culture, tourism, old-age care, health, education, the Internet, finance and other industries and create new forms of sports consumption, so as to further stimulate the potential of people's sports consumption.

\section{PRACTICAL BASIS: RESOLVING THE CONTRADICTION BETWEEN SUPPLY AND DEMAND MISMATCH AND STRUCTURAL IMBALANCE}

\section{A. Quantity of Supply: Surplus of Low-end Supply, Insufficient Effective Supply}

The biggest constraint on China's economy is the inability of supply to meet changing demand, The Wall Street Journal said. Residents' demand for high-quality products and services is growing strongly, while the existing supply is not sufficient to meet demand, that is to say, the contradiction between structural oversupply and structural supply shortage has become prominent.

1) Low-end sports products are in oversupply: In recent years, China's sports goods manufacturing industry has developed rapidly. In 2016, the total output of the manufacturing of sports goods and related products was $1,196.21$ billion yuan, which has become a pillar industry of the sports industry. This development is nurtured by demographic dividend and low barriers to entry, resulting in low-end apparel, shoes, hats and equipment for sports flooding the market. Excess capacity and inventory have become an important factor restricting the development of China's sports industry. Taking sports shoes as an example, in Jinjiang, a city where sports shoes are popular, more than a third of the region's 2 million people live on the chain of the shoe-making industry. After experiencing the peak expansion period relying on purely vertical development, this industry entered the bottleneck period of development. As reported by "Prism", the shoe industry in Jinjiang has spent a decade making shoes that can't be sold out for a century. Since the excess capacity is hard to clear, the shoes industry in Jinjiang had already failed collectively before DEERWAY and xdlong collapsed. Another indicator of excess capacity is low utilization of equipment. The "2015• Follow-up Survey Report of Chinese Enterprise Managers" shows that nearly $60 \%$ of enterprises have equipment utilization rate lower than $75 \%$, which is lower than the normal utilization rate of $80 \%$.

2) Medium- and high-end sports products are in short supply: The phenomenon of insufficient supply of middle and high-end sports products is more obvious, and it is difficult to meet the needs of residents' diversified, personalized and high-end sports demand, resulting in a huge supply gap. Driven by national strategies such as nationwide fitness programs programs and Healthy Chinese, 
insufficient supply quantity and low supply efficiency. According to "The Sixth Survey of Sports Venues", there were 1.6946 million sports venues in China in 2013, with a total population of 1.361 billion. The average number of venues per 10,000 people was 12.45 . In 2015 , the per capita space reached $1.57 \mathrm{~m}^{2}$, less than $1 / 10$ of the corresponding value in the United States a few years ago, less than 1/12 of Japan and $1 / 15$ of western developed countries [3]. On the other hand, although the per capita area of site has reached $1.57 \mathrm{~m}^{2}$, the usable per capita site area of human settlements is far lower than per capita site area due to the low opening rate of the existing venues, which are mainly concentrated in the education, military and sports systems. As many as 665,500 venues are managed by the education system in China, accounting for $53.01 \%$ of the country's total. As the closest and most suitable venue for the public, its opening rate is less than one third.

3) With the investment funds of sports from a single source, the return is not high: The sources of investment funds mainly include financial input, bank loans, social financing, foreign capital and internal capital of enterprises. The source of China's sports industry capital investment is relatively single. In the core areas of sports industry, the state-owned and collective economic units account for a large proportion, especially in sports organization and management activities and stadium management activities, of which the state-owned and collective economic units account for as much as $68.4 \%$ and $51.8 \%$. According to statistics, by the end of 2017, there were 78 A-share sportsrelated companies listed on the Shanghai and Shenzhen Stock Exchanges, among which 22 state-owned enterprises were still mainly funded by national financial investment, while the remaining 56 private enterprises were mostly transferred from other related industries such as real estate, tourism and advertising, and the funds are mainly from the primitive accumulation of companies. As $\mathrm{Li}$ Xudong, managing director of the investment banking division of CITIC construction securities puts it: "there are no listed companies in the sports sector in the A-share market in the strict sense, although some real estate companies are expanding in the sports sector, which accounts for less than 10 per cent of revenues." [4] According to the 2015 annual report, Evergrande suffered a loss of 953 million. As Li Xudong, managing director of CITIC construction investment bank puts it: "there are no strictly listed sports companies in the a-share market, although some real estate companies are expanding into sports, which accounts for less than 10 per cent of revenues." [4] According to the 2015 annual report, Guangzhou Evergrande Taobao Football Club lost 953 million yuan. On the National Equities Exchange and Quotationsnew OTC market, sports listed companies generally lost money, with an average net profit loss of 11 million yuan. According to the CCTV Economic News, 60 percent of health clubs in China are making negative profits. 
demand, and improving the quality and efficiency of the supply system of sports industry, can the contradiction between supply and demand of sports product market be solved. The supply-side structural reform is to improve the adaptability of the supply structure of the sports industry to the demand structure. Only by providing products that fit the consumer preference of the public can the contradiction between supply and demand of the sports goods market be truly solved. According to the characteristics and trends of residents' sports consumption demand, it is necessary to strengthen the interactive feedback between supply and demand, and safeguard the long-term supply-side reform with demand-side management. It is important to guide and direct the production and supply of sports products, improve the adaptability and flexibility of the product supply system, and conform to the changing trend of residents' sports consumption demand structure by use of the market information. In this way, the structural problem of insufficient high-end supply can be solved, and the diversified sports consumption needs of consumers can be met so that the two-way dynamic balance between supply and demand in the short term and the long term can be realized.

\section{B. Improving the Supply System for Sports Products}

The ultimate goal of the supply-side structural reform is to meet the diversified consumption needs of consumers. At the 2016 China Development Forum, the Nobel Prize owner Stiglitz pointed out that, "In the context of insufficient global aggregate demand, China now needs to push for stronger demand-side measures, without which supply-side reforms could backfire." The reform of the supply-side structure of sports industry should mean, following the trend of upgrading sports consumption demand, vigorously promoting the health literacy of the whole people, stimulating new hot spots of sports consumption and cultivating the driving force of sports consumption demand, so as to solve the structural contradiction between rigid supply and elastic demand.

1) Expanding the supply of sports products and services: The shortage of sports products supply is a basic practical problem, whether it is the supply of public products to meet residents' demand for basic sports services, or the supply of high-end sports products to meet residents' personalized demand for high quality. The lack of supply restricts the residents' demand for sports consumption. Without scale, structural adjustment is out of the question, and without structural optimization and adjustment, improving supply efficiency will become empty talk. It is necessary to increase the supply scale of high-quality sports products and services, enrich consumers' consumption choices, and meet residents' demand for sports consumption by increasing the quantity and optimizing the stock.

2) Improving the quality of sports products and services. Innovation should be put at the core of the development of the sports industry to build a soft power for the development of the sports industry and sports enterprises should be supported in technological transformation and equipment 
industry and improve the structure. On the other hand, it is also important to emphasize the improvement of the quality of the labor force, turn "demographic dividend" into "human capital dividend", and upgrade the supply of labor factors.

2) Strengthening social services in sports venues. Efforts should be made to increase the supply of public sports products, encourage nongovernmental forces to hold sports events, optimize the layout and structure of existing stadiums and gymnasiums and facilities in schools and sports systems, take the initiative to meet the needs of residents for sports and fitness, and improve the utilization rate of public sports facilities. It is necessary to actively attract nongovernmental forces to run sports causes, expand sources of funds and channels, and increase the total supply of public goods such as stadiums and gymnasiums, sports events, and sports training. In the form of social selfmanaged financing and disbursement, social capital should be provided with reasonable return on investment, and it should be introduced into the supply of sports public services, so as to increase the total supply of sports public products.

3) Reducing the financing costs of corporates: It is necessary to build a financing platform to promote the healthy growth of sports industry, reduce the financing threshold and cost of market players, and improve the allocation efficiency of sports capital market. In the field of providing public services, the PPP cooperation model can be adopted to ease the financial pressure of the government, and with the help of private capital, the construction of stadiums and gymnasiums can be strengthened to improve the operation level and utilization rate of stadiums and gymnasiums. In the field of private economy, the problem of financing difficulties of small and medium-sized enterprises can be solved by setting up sports industry development fund and support funds. In view of the actual situation that sports enterprises lack loan collateral, enterprises are allowed to use intangible assets such as trademarks, technologies and scientific research achievements as collateral to obtain credit funds. In the field of direct financing, the proportion of direct financing can be gradually increased through the development of equitybased crowdfunding, equity and equity trading markets, etc., so as to build a multi-level capital market and reasonably meet the financing needs of enterprises of different sizes.

4) Implementing an innovation-driven strategy: It is necessary to accelerate the implementation of the innovation-driven strategy, improve the internal incentive mechanism for scientific and technological innovation, and increase the output and conversion rates of scientific and technological communication. Efforts should be made to stimulate enterprises' vitality of innovation, so that they can actively use new craft and new technology on the basis of existing OEM. In this way, the product structure and technical structure of the traditional sports manufacturing industry should be reformed to improve the efficiency of force. On the one hand, it is important to pay attention to increase the participation rate of labor force in the sports 
labor, technology and capital, so as to improve the total factor productivity and truly realize the transformation from factor-driven to innovation-driven and improved total factor productivity. Therefore, competitive new products with good quality, good brand and popular with consumers can be created, product quality and the adaptability of sports industry supply to social demand can be improved, so as to meet the needs of consumers.

5) Improving the policy system for the development of the sports industry: It is necessary to improve the market economy and increase the supply of new institutions through reform. It is urgent to formulate special laws and regulations to accelerate the development of sports industry and improve the legal effect of sports industry policies to provide a good legal environment for the development of sports industry, and improve the modern property rights system. Price controls should be liberalized to provide markets and investors with real and reliable price signals. It is also necessary to reduce the transaction costs and taxes of enterprises, further consolidate related taxes, reduce production costs, and increase after-tax returns on labor and capital, so as to reduce taxes, profits, restrictions and burdens on enterprise innovation, and stimulate the increase in the supply of labor and capital. Policies for sports and fitness consumption should also be formulated. And the methods such as government purchase, awards instead of subsidies, free opening of venues, popularization of fitness knowledge, and promotion of sports projects, etc. can be used to actively cultivate and guide residents' sports consumption behavior and expand the size of the sports market.

\section{Promoting the Integrated Development of "Sports Plus" and Expanding the Sports Industry Chain}

"Sports + " is a comprehensive combination of industries led by sports that can meet the new needs of residents and create new supply. It focuses on improving the quality and efficiency of the supply system of sports products and services, and provides new ideas, new models and new forms of business for the development of sports industry. Efforts should be made to enrich the supply of integrated "sports +" products and services, expand and improve the sports industry chain, promote the rapid integrated development of sports industry and health, medical care, old-age care, tourism and other industries, expand the market space for sports consumption, and meet the diversified needs of the public for sports consumption.

\section{CONCLUSION}

The outline of the plan for the construction of a sports power proposes to build the sports industry into a pillar industry of the national economy. Yet at present, the total scale of sports industry development is still far from the criterion of pillar industry. It is important to follow the changing trend of residents' sports consumption demand, with improving the supply structure of the sports industry as the main direction and promote the structural reform of the sports industry from both supply and demand sides, thus to ensure the high-quality operation of the sports industry.

\section{REFERENCES}

[1] Jia Kang. Supply-side Reform During the 13th Five-year Plan Period [J]. Journal of China National School of Administration, 2015, 6: 12 21. (in Chinese)

[2] Yi Jiandong. Current Situation, Opportunity and Challenge of Sports Industry in China [J]. Journal of Wuhan Institute of Physical Education, 2016, 50(7): 6-8. (in Chinese)

[3] Huang Daoming. Supply Dilemma and Governance Countermeasures of China's Sports Industry from the Perspective of "Supply-side Reform" [J]. China Sport Science and Technology, 2018, (54) 2: 1522. (in Chinese)

[4] Jing Linbo. An Overview of Sports Industry in China: Current Situation, Problems and Countermeasures [J]. Journal of Nanjing Sports Institute, 2016, 30 (4): 1-10. (in Chinese)

[5] Wang Qian, Fang Qianhua. Spatio-temporal Patterns of Sports Technological Innovations of Path Selection of National Patent Strategy for China [J]. Journal of Xi'an Physical Education University, 2011, 28(3): 76-78. (in Chinese)

[6] Ming Yu, Si Huke. Analysis of Technological Innovation by Foreign Sports Brand Producers of Nike, Adidas, Puma, Reebok and Converse Patent R \& D. Journal of Xi'an Physical Education University, 2015, 32(4): 435-440. (in Chinese)

[7] Liu Yuanxiang. Policy Research on Promoting the Optimization of Sports Industry Structure [J]. Journal of Shandong Institute of Physical Education and Sports, 2017, 33(1): 1-5. (in Chinese)

[8] Zhang Zhenfeng. The Route of the Sports Industrial Transformation of Development under Increasing Sports Consumption Requirements Perspective [J]. Journal of Xi'an Institute of Physical Education, 2017(34), 4: 453-458. (in Chinese) 